\title{
Proposta de uma máquina para colheita mecanizada de babaçu (Orbignya phalerata Mart.) para a agricultura familiar
}

\author{
Daniel ALBIERO ${ }^{1}$, Antonio José da Silva MACIEL ${ }^{2}$, Antonio Cândido LOPES³, Claudia Assad MELLO \\ Carlos Antonio GAMERO5.
}

\section{RESUMO}

O babaçu é uma planta de importância capital na economia de subsistência do norte do Brasil. Sua configuração sócio-ambiental o torna destaque na situação regional amazônica, onde os produtos advindos do babaçu possibilitam renda para a camada mais pobre da população amazônica, além da questão ambiental que é conotada à preservação dos babaçuais naturais. Um dos gargalos técnicos da produção do babaçu, em especial visando a extração do óleo de babaçu, é a colheita feita de forma manual e no sistema extrativista. O objetivo deste trabalho é propor o conceito de uma colhedora de babaçu moto-mecanizada, capaz de trabalhar em cultivos artificiais, assim como em florestas naturais. Foi utilizada a metodologia de projeto da matriz morfológica, onde foram elencadas as possíveis combinações de mecanismos e elementos para uma colhedora de babaçu. Como resultado foi obtido um conceito teórico, sendo concluída a viabilidade técnica de tal projeto, em estudos futuros pretende-se desenvolver estudos de viabilidade técnica detalhados, assim como estudos de viabilidade econômica.

PALAVRAS-CHAVE

Babaçu, Colhedora, Matriz morfológica

\section{Proposal of harvest's babaçu machine (Orbignya phalerata Mart.) for the small farms}

\begin{abstract}
The babaçu is an important plant in subsistence economy in northern Brazil. The environment-social configuration of babaçu is prominent in the Amazonian regional situation, where its products are a means of income for the more impoverished Amazonian population, besides the question of the environment, which is relative to its preservation in the forest. One of the technical obstacles to babaçu production, especially with regard to extracting its oil, is manual harvesting and extractive system. The objective of this work is to propose motorized harvesting in both artificial and natural forests. It was used the project methodology morphological matrix, that numbering the possible configurations os mechanism and elements for the babaçu's harvest. The result was a theoretical concept, it has been concluded the technical viability of project, future studies they intend to develop the detail technical viability as well as the economic viability.
\end{abstract}

KEYWORDS

Babaçu, Harvest's machine, Morphological matrix.

\footnotetext{
1,23,4,Faculdade de Engenharia Agrícola da Universidade Estadual de Campinas - FEAGRI/UNICAMP, Cidade Universitária Zeferino Vaz, Caixa Postal 6011, CEP: 13083-875, Campinas - SP - Brasil, Telefone: 019-3521-1054, Fax: 019-3521-1005, email: daniel.albiero@agr.unicamp.br.

${ }^{5}$ Faculdade de Ciências Agronômicas da Universidade Estadual Paulista - Campus Botucatu, Fazenda Lageado, Rodovia Alcides Soares, Km 3, Caixa Postal 237 CEP: 18610-307, Botucatu - SP- Brasil, Telefone/Fax: 014-3811-7100, email: gamero@reitoria.unesp.br
} 


\section{INTRODUÇÃO}

\section{O BABAÇU}

Babaçu é o nome genérico dado às palmeiras oleaginosas pertencentes à família Palmae e integrantes dos gêneros Orbignya e Attalea. O primeiro gênero inclui espécies predominantemente nativas da região norte do Brasil (Maranhão, Piauí, Pará e (Tocantins), tais como: Orbignya phalerata Mart. (babaçu verdadeiro), Orbignya eichleri Drude (piaçava), Orbignya teixeirana Bondar (perinão) e Orbignya microcarpa Martius. O segundo gênero abrange espécies encontradas principalmente nos estados de Goiás, Minas Gerais e Bahia, dentre as quais se destacam: Attalea oleifera Barb. Rodr. (catolé-de- pernambuco) e Attalea pindobassu Bondar (pindobaçu), Orbignya phalerata é a espécie de maior distribuição, de maior variação morfológica e de maior importância econômica. Esta espécie ocupa regiōes extensivas no Brasil, na Bolívia e no Suriname (Zylbersztajn et al., 2000). O babaçu é nativo da zona de transição entre o cerrado e as florestas abertas do sul da Amazônia, onde invadiu áreas perturbadas pelo homem e formou populaçōes oligárquicas (Clement, 2005).

A distribuição no território brasileiro do babaçu é apresentada na Figura 1 (MIC/STI (1982 apud Teixeira, 2002).

O babaçu destaca-se entre as palmeiras encontradas em território brasileiro pela peculiaridade, graça e beleza da estrutura que lhe é característica: chegando a atingir entre 10 a 20 metros de altura, suas folhas mantêm-se em posição retilínea, pouco se voltando em direção ao solo; orientando-se para o alto, o babaçu tem o céu como sentido, o que lhe dá uma aparência bastante altiva (USP, 2006).

Atualmente, no Brasil, encontram-se vastos babaçuais espalhados ao sul da bacia amazônica, onde a floresta úmida cede lugar à vegetação típica dos cerrados. São os Estados

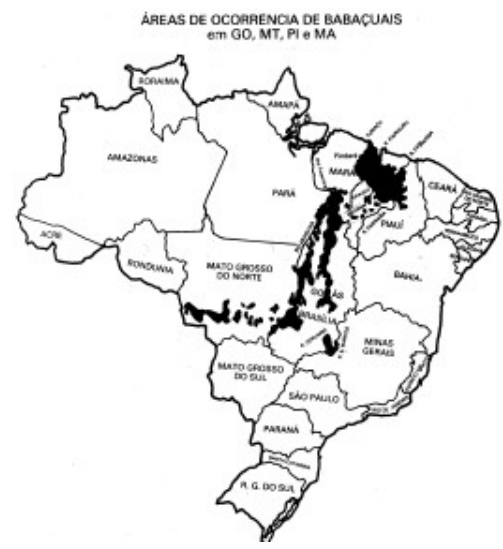

Figura 1 - Distribuição geográfico dos babaçuais no Brasil (MIC/STI, 1982). do Maranhão, Piauí e Tocantins que concentram as maiores extensões de matas onde predominam os babaçus, formando, muitas vezes e espontaneamente, agrupamentos homogêneos, bastante densos e escuros, tal a proximidade entre os grandes coqueiros.

É muito provável que nessa mesma região, antes mesmo dos europeus aqui aportarem, já existissem babaçuais de relevante significado para as populaçôes indígenas locais. Câmara Cascudo nos conta que, já em 1612, o frei viajante Claude d'Abbeville informava sobre a importância dos "frutos da palmeira" na alimentação dos indígenas do nordeste do Brasil, "lá nas bandas de Pernambuco e Potiú" Tal palmeira era, provavelmente, o babaçu, batizada na língua tupi de uauaçu. No entanto, estes antigos babaçuais estavam diluídos em meio a áreas de alta complexidade e variedade biológica, de forma muito diferente do que ocorre atualmente: vastos e homogêneos babaçuais crescendo sem parar (USP, 2006).

Segundo May (1990) os desmatamentos periódicos com queimadas sucessivas foram os principais causadores do grande aumento dos babaçuais, especialmente na Região Nordeste do Brasil. Estas práticas, relacionadas a uma agricultura itinerante, são freqüentemente utilizadas com o objetivo de eliminar os próprios babaçuais tendo, porém, um efeito contrário. Explica-se: logo após uma grande queimada, são justamente as "pindovas" de babaçu - palmeirinhas novas - as primeiras a despontar. Isto porque, sabe-se hoje, o babaçu é extremamente resistente, imune aos predadores de sementes e tem uma grande capacidade e velocidade de regeneração. Com a queima do babaçual e da vegetação ao seu redor, seus principais competidores vegetais são eliminados, abrindo maior espaço para o seu desenvolvimento subseqüente.

\section{CONTEXTO DE PRODUÇÃO}

Em áreas de babaçu denso, a biomassa total é de 69,1 toneladas de peso seco por hectare. A produção anual de folhas é de 16,8 toneladas de peso seco por hectare. A alta produção de folha do babaçu permite aos agricultores obter combustível suficiente para realizar a agricultura itinerante. Para o estabelecimento das culturas anuais intercaladas com o babaçu, no sistema itinerante, algumas palmeiras são eliminadas o que, além de permitir o crescimento das culturas, assegura que uma variedade de bens de subsistência e de mercado oriundos do babaçu possa ser obtida durante o período de descanso. Em densidades variando de 141 a 160 palmeiras por hectare em todas as classes de idade, estimou a produtividade máxima atingida pelos babaçuais da região dos Cocais em 2,1 ton de coco por hectare (MAY, 1990). Já Kono (1981), em inventário realizado em 1.400 hectares de babaçuais localizados no município de Codó (MA), obteve uma produtividade média de 2,5 ton/ha/ano. Segundo Zylbersztajn (2000), a espécie com maior produção de frutos é 
a Orbignya oleifera foi descrita por Burret em 1938 a partir de material coletado em Pirapora, Minas Gerais, as características anatômicas desta espécie lhe conferem maior produtividade do que $O$. phalerata: produção de frutos: 5 ton/ha/ano e $10 \%$ a $22 \%$ de amêndoas no fruto. Segundo Vivacqua Filho (1968) a safra do babaçu vai de setembro a março.

O principal produto do babaçu é o óleo da amêndoa, constituindo $65 \%$ do peso da amêndoa, esse óleo é subproduto para a fabricação de sabão, glicerina e óleo comestível, mais tarde transformado em margarina, e de uma torta utilizada na produção de ração animal e de óleo comestível (USP, 2006).

Segundo Frazão (2001), a produção média de frutos de babaçu é de $2400 \mathrm{~kg} / \mathrm{ha}$, destes $1780 \mathrm{~kg}$ (74\%) são respectivos a Endocarpo/Epicarpo; $480 \mathrm{~kg}$ (20\%) mesocarpo; e $140 \mathrm{~kg}$ (6\%) amêndoas, das amêndoas tem-se 91 litros de óleo.

A partir da polpa da semente, o processo de obtenção do óleo pode ser obtido por processos tradicionais, seguido apenas da neutralização e purificação deste óleo onde através de uma reação de transesterificação com metanol ou etanol podemos chegar no biodiesel que é um combustível limpo e renovável apropriado para movimentar veículos ciclo diesel (Lopes, 1983).

Segundo Zylbersztajn et al. (2000) o esmagamento do coco babaçu produz dois tipos de óleos: um para fins comestíveis e outro para fins industriais (óleo láurico). A utilização do óleo de babaçu para fins comestíveis tem sofrido declínio constante, em virtude de duas razões: a substituição por óleos mais acessíveis, e a tendência dos consumidores a optarem por óleos e gorduras não saturadas.

A baixa produtividade dos babaçuais está relacionada à uma série de fatores, dentre os quais destacam-se: a alta incidência de plantas improdutivas, a relação desequilibrada entre inflorescências masculinas e femininas $(5: 1)$ nas palmeiras adultas produtivas e a idade das plantas. $\mathrm{O}$ babaçu requer entre 10 a 12 anos para iniciar a produção, atingindo a maturidade produtiva entre 15 a 20 anos (May, 1990; Frazão, 1992).

A EMBRAPA (1984) define os seguintes parâmetros climáticos para a produção do babaçu: 1. Insolação mínima de 2400 horas anuais ou radiação total mensal de $360 \mathrm{cal}^{-2} \mathrm{~m}^{-2} ; 2$. Evapotranspiração no trimestre seco não superior a $280 \mathrm{~mm}$. Corresponde à Setembro - Outubro - Novembro, porém, se a acima do paralelo $3^{\circ}$ Sul, desloca-se para Junho - Julho Agosto. Na região Central, concentra-se nos meses de Julho - Agosto - Setembro; 3. Precipitação anual não inferior a 1700 $\mathrm{mm} ; 4$. Umidade suficiente na área das raízes, no período de maior deficiência (3 meses mais secos), não deve passar de $400 \mathrm{~mm} ; 5$. Ventos abaixo de $3 \mathrm{~m} / \mathrm{s}$; e 6 . Preferência por vales orientados Leste - Oeste para maximizar umidade e horas de insolação.

\section{IMPORTÂNCIA ECONÔMICA}

Apesar de sua exploração estar baseada num extrativismo primário, o babaçu desempenhou até meados da década de 80, importante papel na economia do Estado do Maranhão, como base da sustentação de um parque industrial de extração de óleo vegetal, instalado exclusivamente para processar as amêndoas oleaginosas extraídas do seu fruto.

As décadas de 60 ao início de 80 constituíram-se no auge da economia babaçueira, neste período 52 empresas de médio e grande porte funcionavam no Maranhão, produzindo óleo para o abastecimento das indústrias alimentícias, higiene e limpeza no país e no exterior (Herrmann et al., 2001). A partir de 1990 com a abertura das importaçôes, e da globalização da economia mundial, o óleo de babaçu produzido por um extrativismo primário, encontrou um forte concorrente no mercado nacional de óleos láuricos. Importado da Filipinas, o óleo de palmiste (semente de dendê) produzido a partir de plantios industriais com altas produtividades é vendido no mercado nacional por preços equivalente a cerca de $70 \%$ do preço do óleo de babaçu (Frazão, 2001).

A proporção da renda derivada da venda das amêndoas corresponde a aproximadamente $30 \%$ da renda familiar. Esta renda é especialmente importante na entresafra das culturas anuais, quando chega a responder por $42 \%$ de todo o dinheiro ganho. A proporção diminui para $6 \%$ durante o período de maior necessidade de mão-de-obra na colheita do arroz e de crescente escassez de frutos de babaçu acessíveis. Embora a maior parte das amêndoas extraídas seja vendida uma pequena proporção (5\%) é destinada para uso doméstico. Das amêndoas, as populaçôes locais obtêm leite de coco que é utilizado no preparo de carnes, doces e também em bebidas puras ou misturadas com café (May, 2000).

O óleo de soja é o principal concorrente do óleo de babaçu no mercado de óleos comestíveis. O mercado brasileiro formal para o óleo de babaçu comestível é estimado em 5,5 mil toneladas/ano, predominantemente para o mercado do nordestino. Além deste, existe um mercado informal caracterizado pelo autoconsumo das famílias de baixa renda localizadas nas regióes de ocorrência da palmeira. O mercado brasileiro de óleos láuricos constitui-se atualmente no principal mercado para o óleo de babaçu. As indústrias dos segmentos de higiene, limpeza e cosméticos absorvem 35 mil toneladas anuais de óleo de babaçu bruto. Além do mercado de láuricos, o babaçu começou a adquirir importância para algumas empresas da indústria siderúrgica, interessadas na possibilidade de utilização do coco carbonizado como carvão vegetal, em substituição ao carvão oriundo de matas nativas (Zylbersztajn et al., 2000). A casca do coco, devidamente preparada, fornece um eficiente carvão, fonte exclusiva de combustível em várias regiōes do nordeste do Brasil. A população, que sabe aproveitar das riquezas que possui, realiza freqüentemente o processo 
de produção do carvão de babaçu durante a noite: queimada lentamente em caieiras cobertas por folhas e terra, a casca do babaçu produz uma vasta fumaça aproveitada como repelente de insetos (Biodiesel BR, 2006).

A venda de amêndoas de babaçu representa para os pecuaristas receitas brutas de US\$18.40/ha que em receitas líquidas representa US\$ 4.60/ha por ano. Embora estas receitas pareçam baixas, quando comparadas com a renda proveniente da pecuária (US\$ 15.45) representam uma renda adicional de quase um quarto dos rendimentos líquidos por hectare provenientes de ambas as atividades. O babaçu além de ser uma fonte importante de renda para as populaçôes locais que o extraem, o é também para a economia regional como um todo através da industrialização do óleo de babaçu que na década dos 80 atingiu uma produção de 80.000 toneladas/ ano, o que gerou um valor no mercado final de 40 milhōes de dólares (May, 2000).

O óleo de babaçu quando transformado em biodiesel pode ser uma alternativa econômica viável já que o combustível é produzido no próprio local de uso que normalmente são regiōes isoladas do nosso país (Lopes, 1983).

Wunder (1998) afirma que o subsetor extrativista da agricultura recebe muita atenção internacional pelo potencial que lhe é atribuído para o uso sustentável das florestas tropicais e de outros ecossistemas naturais, por exemplo, com a colheita de produtos nãomadeireiros nas reservas extrativistas, neste contexto o babaçu recebe especial atenção.

\section{IMPORTÂNCIA SOCIAL}

Todo o babaçu é produzido pela população extremamente pobre da região amazônica por absoluta falta de outras oportunidades. Eles extraem os caroços do fruto lenhoso, um trabalho penoso. Os caroços são vendidos às fabricas para a extração do óleo ou são transformadas em óleo de forma caseira para o consumo da família (Clement, 2005).

Segundo May (2000) no sistema agrícola praticado pelos pequenos agricultores familiares, o babaçu funciona como um gerador de biomassa na queima intensiva da mata secundária, necessária para fornecer nutriente, reduzir infestaçōes de ervas daninhas e limpar o terreno para o cultivo. $\mathrm{Na}$ maioria dos sistemas de cultivo associados ao babaçu, os agricultores não controlam a terra. $\mathrm{O}$ acesso a ela se dá por meio de acordos com os proprietários. Geralmente as famílias dos pequenos produtores recebem moradia, uma gleba de terra para cultivar e obter o usufruto dos recursos extrativistas, dando em troca o pagamento de uma renda em espécie, geralmente arroz. Sob este sistema, o direito de usufruto do babaçu está relacionado ao acesso à terra. A quebra do coco para a extração da amêndoa é tida como "trabalho de mulher". Considerando o tempo total dedicado por uma família à extração da amêndoa, $81 \%$ do trabalho é realizado por mulheres e crianças em quanto que na agricultura a participação do homem é maior. Das amêndoas também extraem o óleo para cozinhar, o sabão e um substituto do querosene usado em lamparinas. Do endocarpo lenhoso que abriga as amêndoas é produzido o carvão que é utilizado pelas famílias para satisfazer as necessidades de combustível, contribuindo assim para proteger as florestas da coleta excessiva de madeira para fins energéticos.

Zylbersztajn et al. (2000) informa que em média, uma quebradeira de coco extrai cerca de $5 \mathrm{~kg}$ de amêndoas em um dia de trabalho, embora algumas pessoas consigam extrair até $15 \mathrm{~kg}$. Existe uma forte questão de gênero ligada à atividade de quebra do babaçu. Por constituir-se na única fonte de renda gerada exclusivamente pelas mulheres no âmbito familiar, o trabalho de quebra adquiriu uma conotação de liberdade no imaginário feminino. A luta das quebradeiras de coco babaçu por melhorias no exercício da sua atividade originou duas organizaçōes de peso no rural maranhense: a Associação das Mulheres Trabalhadoras Rurais (AMTR) e o Movimento Interestadual das Quebradeiras de Coco Babaçu (MIQCB). O babaçu é integralmente aproveitado pelas famílias que sobrevivem da agricultura de subsistência associada à exploração da palmeira. A amêndoa que não é comercializada é utilizada para a produção de óleo e de leite para o consumo doméstico. $\mathrm{O}$ mesocarpo do coco é utilizado tanto na alimentação humana quanto na alimentação animal. Do endocarpo é produzido o carvão, utilizado como combustível na cocção dos alimentos. As folhas secas (palha) são utilizadas para a confecção dos telhados das moradias. Cerca de 5\% das amêndoas coletadas são aproveitadas para consumo doméstico pelas famílias rurais. O restante é comercializado em troca de gêneros alimentícios.

May (2000) afirma que além de utilizar a casca para produzir carvão, as famílias utilizam o mesocarpo que apresenta $60 \%$ de amido, o que o torna uma excelente fonte de carbohidrato para alimentação de porcos e aves. Em tempo de escassez, a farinha do mesocarpo (fubá) é utilizada como alimento pelas populações rurais. Adicionando água à farinha se produz o mingau considerado pelos entrevistados um excelente remédio para males gastrointestinais.

Quanto menor é a renda familiar maior é a importância relativa da renda proveniente do babaçu. $\mathrm{O}$ que segundo o autor sugere que qualquer mudança que venha a afetar o acesso às palmeiras tem sérias conseqüências para o bem-estar dos estratos sociais mais pobres da região. As diferenças na importância relativa da renda proveniente do babaçu são em função da situação econômica dos produtores. Assim, para os trabalhadores assalariados a proporção da renda proveniente das vendas das amêndoas representa $25 \%$ contra somente $11 \%$ para os minifundiários e posseiros (May, 2000). 


\section{CONTEXTO AMBIENTAL}

As palmeiras de babaçu e os sistemas de produção agrícola regionais estão intimamente ligados na zona de babaçu, de uma maneira que pode ser descrita como práticas agroflorestais. A produção de culturas anuais e pastoreio é feita sob as palmeiras que se auto- propagam (May,2000).

Do babaçu tudo se aproveita, também como acontece com a maioria das palmeiras. Especialmente nas economias de subsistência e em regiōes de pobreza. Suas folhas servem de matéria-prima para a fabricação de utilitários - cestos de vários tamanhos e funçóes, abanos, peneiras, esteiras, cercas, janelas, portas, armadilhas, gaiolas, etc. - e como matériaprima fundamental na armação e cobertura de casas e abrigos. Durante a seca, essas mesmas folhas servem de alimento para a criação. O estipe do babaçu, quando apodrecido, serve de adubo; se em boas condições, é usado em marcenaria rústica. Das palmeiras jovens, quando derrubadas, extrai-se o palmito e coleta-se uma seiva que, fermentada, produz um vinho bastante apreciado regionalmente (USP, 2006).

Segundo HOMMA (2005) a redução dos desmatamentos e queimadas na região amazônica depende do desenvolvimento de atividades agrícolas adequadas nas áreas já desmatadas e que tenham mercado, sendo o babaçu adequado para tal.

\section{CONTEXTO TÉCNICO}

Em relação a pouca produtividade Zylbersztajn (2000) sugere investimentos em pesquisa para o desenvolvimento de variedades melhoradas de babaçu com as seguintes açôes: (i) buscar fundos públicos e privados para P\&D; (ii) definir os direitos de propriedade sobre os resultados gerados; (iii) definir mecanismos de transferência de riscos1; (iv) propor mudanças na legislação estadual que incentivem a sua utilização comercial (principalmente a questão da reposição florestal, tamanho das reservas e derrubadas); (v) definir linhas de pesquisa prioritárias.

Em relação ao sistema de colheita Frazão (2001) sugeriu um sistema de coleta onde os cocos sejam coletados e transportados até a unidade de beneficiamento em volumes consideráveis. Para facilitar a coleta e transporte dos cocos, foram introduzidos animais de cargas que atrelados com cangalha e jacá fazem o transporte até a uma carroça as quais transportam o equivalente a $1,00 \mathrm{~m}^{3}$ de coco até a unidade de processamento. $\mathrm{O}$ tipo de animal a ser usado deve ser respeitar as tradiçóes locais, entretanto em áreas onde existem caminhos em boas condiçōes e a topografia seja favorável, recomenda-se o uso de jumentos, pois são animais dóceis e de fácil lida pelas mulheres. Segundo May (1999) citado por Teixeira (2002), um sistema de coleta dos frutos do babaçu mais eficiente consiste no recolhimento dos frutos em jacás que são transportados por mulas até a margem da estrada mais próxima, onde são transladados para "Big Bags" de 750 $\mathrm{kg}$ cada, com o uso de um caminhão com braço hidráulico articulado, estes são recolhidos e encaminhados para o uso final, Figura 1.

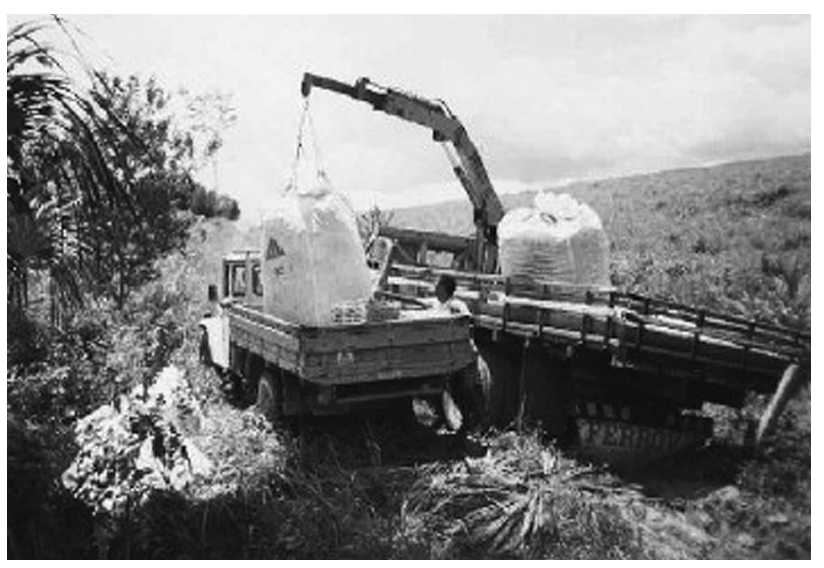

Figura 2 - Sistema de transporte (Teixeira, 2002).

A falta da percepção de que o gargalo da economia babaçueira esta no suprimento de coco e não na sua tecnologia de quebra teve um custo muito alto para aqueles que se envolveram neste negócio (Zylbersztajn, 2000).

Percebe-se pela literatura que a questão da quebra do coco de babaçu, apesar de difícil e onerosa é importante fonte de emprego e renda para a população pobre da região amazônica, além de não representar entrave na cadeia produtiva do óleo de babaçu. Os pontos nevrálgicos do problema são a pouca produção do babaçu e a colheita dos frutos que requer muito tempo devido a necessidade de coleta manual e meio de locomoção a pé por entre a floresta ou cultivo, perfazendo um sistema de colheita pouco eficiente.

$\mathrm{Na}$ questão da colheita dos frutos do babaçu, a literatura sugere sistemas de coleta, não de colheita. A hipótese deste trabalho é de que um sistema mecanizado de colheita de babaçu pode melhorar a eficiência de colheita do fruto, eliminando o processo de coleta aumentando a eficiência do processo.

O objetivo deste trabalho é propor uma máquina conceitual para a colheita de babaçu. Será utilizado o método morfológico, que segundo Back (1983), consiste numa pesquisa sistemática de novas combinaçôes de elementos ou parâmetros com o objetivo de encontrar um novo conceito útil.

\section{MATERIAL E MÉTODOS}

Segundo Back (1983), quando um projeto é iniciado e desenvolvido, este se desdobra se em uma seqüência de eventos, numa ordem cronológica, formando um modelo, 
cada um destes eventos pode ser dividido em fases.

Segundo Dandy \& Warner (1989) a intenção do método morfológico é forçar uma ordenação de uma situação de problema difuso, e descobrir combinaçôes de fatores que não seriam ordinariamente desenvolvidos por um processo normal.

O método morfológico trabalha melhor quando o problema pode ser dividido em componentes ou subproblemas, onde cada sub-problema deveria representar uma significante e identificável parte do problema maior (Dandy \& Warner, 1989).

Esta seqüência de eventos tem suas fases convencionadas pelos seguintes gráficos na Tabela 1 (Back, 1983):

Tabela 1 - Convenções de fases no processo de projetar (Back, 1983).

\begin{tabular}{lll} 
Fase do evento & Representação Gráfica & Descrição \\
Processo & $\begin{array}{l}\text { Processo ou operação } \\
\text { executada }\end{array}$ \\
Resultado & $\begin{array}{l}\text { Dados de saída do } \\
\text { processo }\end{array}$ \\
Avaliação & $\begin{array}{l}\text { Comparação de dados e } \\
\text { tomada de decisão }\end{array}$ \\
Dados & $\begin{array}{l}\text { Informações ou dados de } \\
\text { qualquer natureza }\end{array}$ \\
\hline
\end{tabular}

Após a definições destas fases e seu fluxograma, o método morfológico pode ser aplicado segundo os passos descritos por Dandy \& Warner (1989):

\section{DESCRIÇÃO DO PROBLEMA;}

Listagem do principais parâmetros do sistema;

Listagem das alternativas para satisfazer cada parâmetro do sistema;

Montagem da matriz morfológica, nas linhas deve-se colocar os parâmetros, e nas colunas as alternativas.

O fluxograma deste projeto é apresentado na Figura 3.

\section{RESULTADOS E DISCUSSÃO}

Tendo como base o fluxograma apresentado na Figura 3 , e os dados da literatura referente ao babaçu, foi possível determinar as matrizes morfológicas, assim como o desenho conceitual da máquina para colheita de babaçu.

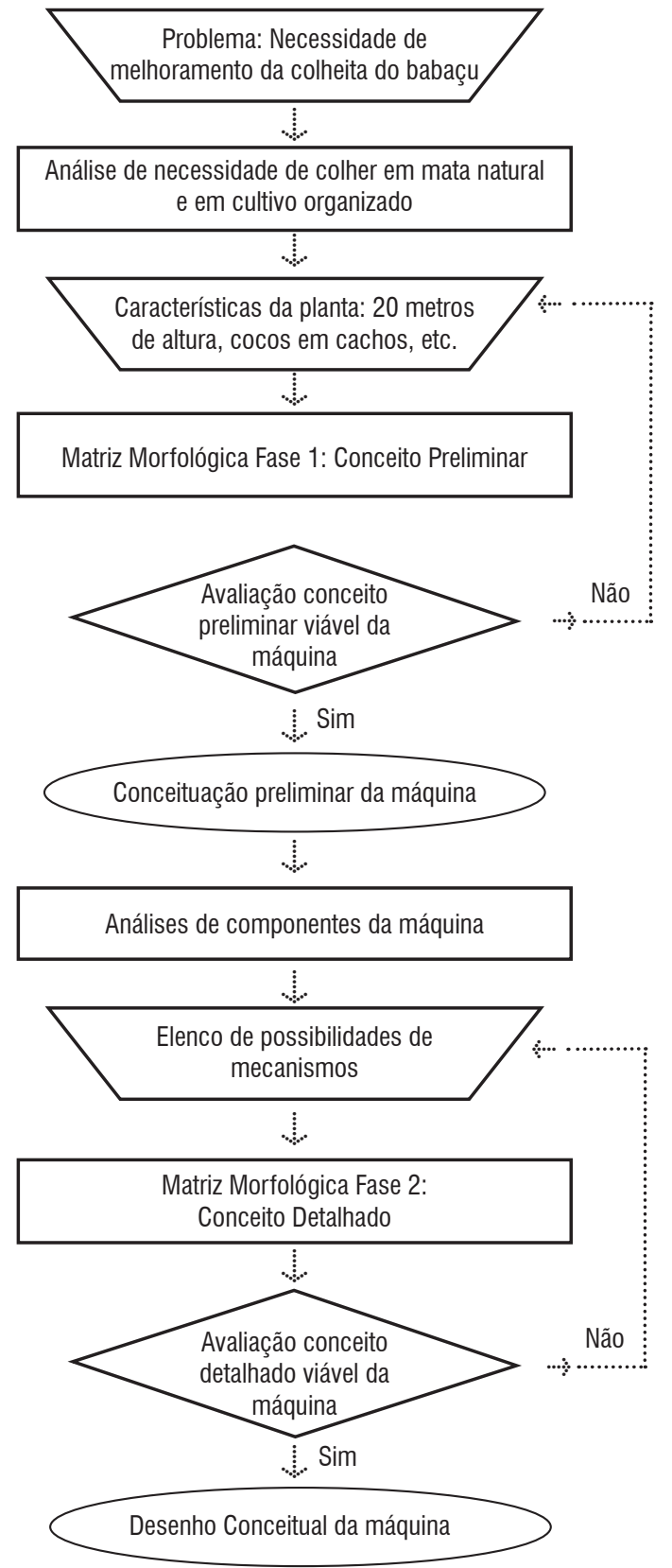

Figura 3 - Fluxograma das fases do projeto de colhedora de babaçu. 
Como problema a ser enfocado, foi considerada a necessidade de se melhorar a eficiência de colheita de cocos de babaçu, tanto em ambiente florestal natural, como artificial. Após estudo da literatura referente a planta do babaçu (morfologia, aspectos de arquitetura de planta, altura, produção, espaçamento e distribuição de babaçus em condiçōes naturais e artificiais de babaçuais) foi possível estruturar a Matriz Morfológica da fase 1: Conceito preliminar, apresentada na Matriz 1.

MATRIZ 1. MATRIZ MORFOLÓGICA DA COLHEDORA DE BABAÇU. FASE 1. CONCEITO PRELIMINAR.

Baseado na matriz 1, foi possível descrever a conceituação preliminar da máquina: A colhedora de babaçu será automotriz, constituída de um trator movido a um motor de combustão interna (CI) com menos que $30 \mathrm{cv}$, certamente um motocultor, operado por uma pessoa, onde será montado um chassi que suportará um sistema de corte dos cachos de babaçu por lâmina (tipo facão), para alcançar os cachos as alturas de até 20 metros, para elevação a lâmina será acoplada a um sistema de pistão hidráulico movido a uma bomba hidráulica, o sistema de elevação e corte terão comandos hidráulicos e manuais, os mecanismos de corte e elevação terão 3 graus de liberdade, significando movimentação nas 3 direções $(\mathrm{x}, \mathrm{y}, \mathrm{z})$. O sistema de recolhimento será manual no chão por outra máquina, ou por pessoas.

Avaliando o conceito de máquina descrito como viável, foi construída a Matriz Morfológica da fase 2: Conceito detalhado, apresentada na Matriz 2, visando detalhar os mecanismos da máquina.

\section{MATRIZ 2. MATRIZ MORFOLÓGICA DA COLHEDORA DE BABAÇU.} FASE 2. CONCEITO DETALHADO.

Baseado na Matriz 2, foi possível descrever a conceituação detalhada da máquina: A colhedora de babaçu será automotriz, constituída de um motocultor movido a um motor de combustão interna $(\mathrm{CI})$ que operará a biodiesel com potência em torno de $10 \mathrm{cv}$, uma possível marca e modelo deste motocultor seria o Bertolini 318, que desenvolve a 2000 $\min ^{-1}, 14 \mathrm{cv}$, a colhedora será operada por uma pessoa que se acomodará sentada no chassi, acoplado ao motocultor e formado por uma treliça de aço que suportará um sistema de corte dos cachos de babaçu por lâmina (tipo facão) de aço tratado termicamente e mecanicamente com geometria linear dos 2 gumes, para alcançar os cachos as alturas de até 20 metros, será projetado um sistema de elevação formado por um pistão hidráulico composto (telescópico), com 5 elementos de 3 metros de comprimento cada, este pistão terá o fluxo de óleo movido a uma bomba hidráulica de pistão, o comando do sistema de elevação será hidráulico enquanto que o comando do corte será manual, os mecanismos de corte e elevação terão 3 graus de liberdade significando movimentação nas 3 direçôes $(\mathrm{x}, \mathrm{y}, \mathrm{z})$ o de elevação será acionado por fluxo de óleo, enquanto que o de corte por cabos de aço, sendo a base do sistema também móvel e com 2 graus de liberdade. O sistema de recolhimento será manual no chão por outra máquina, ou por pessoas.

Matriz 1 - Matriz Morfológica da Colhedora de Babaçu. Fase 1. Conceito Preliminar.

\begin{tabular}{|c|c|c|c|c|c|c|c|c|c|c|c|c|}
\hline & Conceitos & & & & & & & & & & & \\
\hline $\begin{array}{l}\text { Component } \\
\text { es }\end{array}$ & 1 & 2 & 3 & 4 & 5 & 6 & 7 & 8 & 9 & 10 & 11 & 12 \\
\hline $\begin{array}{l}\text { Sistema de } \\
\text { corte }\end{array}$ & $\begin{array}{l}\text { Lâmina } \\
\text { (facâo) }\end{array}$ & $\begin{array}{l}\text { Corrente } \\
\text { dentada } \\
\text { (motoserra) }\end{array}$ & $\begin{array}{l}\text { Gancho } \\
\text { (foice) }\end{array}$ & $\begin{array}{l}\text { Serra } \\
\text { circular }\end{array}$ & fresa & $\begin{array}{l}\text { Serra } \\
\text { linear }\end{array}$ & Laser & Tesoura & & & & \\
\hline $\begin{array}{l}\text { Sistema de } \\
\text { elevaçäo }\end{array}$ & $\begin{array}{l}\text { Escada } \\
\text { (homem } \\
\text { sobe) }\end{array}$ & $\begin{array}{l}\text { Hidráulico/cil } \\
\text { indro }\end{array}$ & $\begin{array}{l}\text { Pneumáticolci } \\
\text { lindro }\end{array}$ & $\begin{array}{l}\text { Motor } \\
\text { elétrict } \\
\text { rosca }\end{array}$ & elétroimãs & $\begin{array}{l}\text { Roldanas }+ \\
\text { cordas }\end{array}$ & $\begin{array}{l}\text { Motor } \\
\text { hidráulicotr } \\
\text { osa }\end{array}$ & Homem escalando & & & & \\
\hline Energia & manual & $\begin{array}{l}\text { Combustăo } \\
\text { interna }\end{array}$ & elétrica & hidraulica & eólica & Animal & & & & & & \\
\hline $\begin{array}{l}\text { Sistema de } \\
\text { locomoção }\end{array}$ & Apé & automotor & Animal & barco & aéreo & anfibio & & & & & & \\
\hline $\begin{array}{l}\text { Número de } \\
\text { operadores }\end{array}$ & 1 & 2 & 3 & 4 & 5 & & & & & & & \\
\hline Comandos & manuais & automáticos & $\begin{array}{l}\text { Semi- } \\
\text { automáticos }\end{array}$ & mecanticos & $\begin{array}{l}\text { Eletro-_- } \\
\text { hidraulicos }\end{array}$ & Hidromeca & $\begin{array}{l}\text { Hidráulicol } \\
\text { manual }\end{array}$ & & & & & \\
\hline $\begin{array}{l}\text { Fonte de } \\
\text { energia }\end{array}$ & Motor CI & $\begin{array}{l}\text { Motor } \\
\text { elétrico }\end{array}$ & $\begin{array}{l}\text { Motor } \\
\text { Citbomba } \\
\text { hidráulica }\end{array}$ & $\begin{array}{l}\text { Motor } \\
\text { citgeradort } \\
\text {-motor } \\
\text { eletrico }\end{array}$ & Animallbu & $\begin{array}{l}\text { strimathbu } \\
\text { (alo) }\end{array}$ & $\begin{array}{l}\text { Animal(mul } \\
\text { a) }\end{array}$ & Animal(cavalo) & Animal(boi) & $\begin{array}{l}\text { Animal(c } \\
\text { abra) }\end{array}$ & $\begin{array}{l}\text { Hom } \\
\text { em }\end{array}$ & \\
\hline $\begin{array}{l}\text { Sistema } \\
\text { motriz }\end{array}$ & $\begin{array}{l}\text { Trator } \\
>100 \mathrm{cr}\end{array}$ & $\begin{array}{l}50 \mathrm{cw}<\text { Trator }< \\
100_{\mathrm{cv}}\end{array}$ & $\begin{array}{l}30 \mathrm{cv} \leqslant \text { Tratore } \\
50 \mathrm{cv}\end{array}$ & Trator $<30 \mathrm{cv}$ & $\begin{array}{l}\text { Motor } \\
\text { CI+gerado }\end{array}$ & $\begin{array}{l}\text { Motor } \\
\text { CItbomba } \\
\text { hidr }\end{array}$ & $\begin{array}{l}\text { Animaltrod } \\
\text { as, polias, } \\
\text { alapancas }\end{array}$ & $\begin{array}{l}\text { Homem+ pedaista } \\
\text { lavancas +manivel } \\
\text { as }\end{array}$ & & & & \\
\hline $\begin{array}{l}\text { Graus de } \\
\text { liberdade } \\
\text { dos } \\
\text { mecanismos }\end{array}$ & $\mathrm{X}$ & $\mathrm{Y}$ & 2 & $X_{X}$ & $\mathrm{Xz}$ & $y^{2}$ & $\begin{array}{l}\mathrm{XYZ} \\
\Delta\end{array}$ & & & & & \\
\hline $\begin{array}{l}\text { Sistema de } \\
\text { suporte }\end{array}$ & $\begin{array}{l}\text { Suportad } \\
\text { o pelo } \\
\text { operador } \\
\text { (costas) }\end{array}$ & $\begin{array}{l}\text { Suportado } \\
\text { pelo operador } \\
\text { (braçøs) }\end{array}$ & $\begin{array}{l}\text { Suportado } \\
\text { pelo operador } \\
\text { (ombros) }\end{array}$ & $\begin{array}{l}\text { Suportado } \\
\text { pelo } \\
\text { operador } \\
\text { (mãos) }\end{array}$ & $\begin{array}{l}\text { Suportado } \\
\text { por animal }\end{array}$ & $\begin{array}{l}\text { Suportado } \\
\text { por trator }\end{array}$ & \begin{tabular}{l|l} 
Suportade & \\
por chassi
\end{tabular} & $\begin{array}{l}\text { Suportado por } \\
\text { tripé }\end{array}$ & & & & \\
\hline $\begin{array}{l}\text { Transporte/ } \\
\text { babaçu }\end{array}$ & carreta & caminhão & $\begin{array}{l}\text { Cestos no } \\
\text { sistema }\end{array}$ & $\begin{array}{l}\text { Sistema de } \\
\text { recolhiment } \\
\text { o mecanice }\end{array}$ & $\begin{array}{l}\text { Recolhime } \\
\text { nto manual } \\
\text { durante } \\
\text { operacao }\end{array}$ & $\begin{array}{l}\text { Recolhime } \\
\text { nto manual } \\
\text { no chão }\end{array}$ & & & & & & \\
\hline
\end{tabular}


Matriz 2 - Matriz Morfológica da Colhedora de Babaçu. Fase 2. Conceito Detalhado.

\begin{tabular}{|c|c|c|c|c|c|c|c|c|c|c|c|c|}
\hline & Conceitos & & & & & & & & & & & \\
\hline $\begin{array}{l}\text { Component } \\
\text { es }\end{array}$ & 1 & 2 & 3 & 4 & 5 & 6 & 7 & 8 & 9 & 10 & 11 & 12 \\
\hline Lâmina & linear & circular & 1 gume & 2 gume & 3 gume & 4 gume & $\begin{array}{l}\text { Facalcontrafa } \\
\text { ca }\end{array}$ & & & & & \\
\hline $\begin{array}{l}\text { Grau de } \\
\text { liber dade } \\
\text { do de corte }\end{array}$ & $\mathrm{x}$ & $y$ & $z$ & $\mathrm{xy}$ & xz & $\mathrm{xz}$ & zyx & & & & & \\
\hline $\begin{array}{l}\text { Acionament } \\
\text { o do corte }\end{array}$ & $\begin{array}{l}\text { engregan } \\
\text { gens }\end{array}$ & cardan & cames & cabos & servomotor & $\begin{array}{l}\text { Hidro- } \\
\text { cilindros }\end{array}$ & $\begin{array}{l}\text { Pneumo- } \\
\text { cilindros }\end{array}$ & Motor elétrico & $\begin{array}{l}\text { Motor } \\
\text { hidraulico }\end{array}$ & & & \\
\hline $\begin{array}{l}\text { Tipo de } \\
\text { metal da } \\
\text { lâmina }\end{array}$ & $\begin{array}{l}\text { Aço } \\
\text { carbono }\end{array}$ & ferro & Ferro fundido & aluminio & ligametalica & 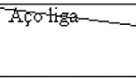 & Acco tratado & $\begin{array}{l}\text { Aço tratado } \\
\text { termicamente e } \\
\text { mecanizamente }\end{array}$ & & & & \\
\hline $\begin{array}{l}\text { Cilindro } \\
\text { elevador }\end{array}$ & único & composto & $\begin{array}{l}\text { Articulado } \\
\text { com } \\
\text { escada } \\
\text { escanismo de }\end{array}$ & & & & & & & & & \\
\hline $\begin{array}{l}\text { Tipo } \\
\text { combustivel }\end{array}$ & diesel & gasolina & $\begin{array}{l}\text { Gás de } \\
\text { petroleo }\end{array}$ & Metano biogas & Biodiese1 & alcool & Bio-oleo & & & & & \\
\hline $\begin{array}{l}\text { Potencia } \\
\text { motor }\end{array}$ & $1 \mathrm{cv}$ & $5 \mathrm{cv}$ & $10 \mathrm{cv}<$ & $-20 \mathrm{cr}$ & $30 \mathrm{cv}$ & & & & & & & \\
\hline Trator & agrale & bertoline & tobata & yamar & $\mathrm{JD}$ & $\mathrm{MF}$ & Case & $\mathrm{NH}$ & Valtra & & & \\
\hline $\begin{array}{l}\text { Posicão } \\
\text { operadores }\end{array}$ & $\begin{array}{l}\text { Sentado } \\
\text { no chassi }\end{array}$ & $\begin{array}{l}1 \text { Sentado no } \\
\text { chassi+ _em }\end{array}$ & $\begin{array}{l}1 \text { Sentado no } \\
\text { - Monobtóco } \\
+1 \text { em pé }\end{array}$ & $\begin{array}{l}\text { Sentadono } \\
\text { monobloco }\end{array}$ & 2 empé & & & & & & & \\
\hline Comandos & 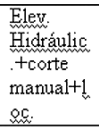 & $\begin{array}{l}\text { Elev manuat- } \\
\text { tcorte } \\
\text { manual+loco } \\
\text { moc. manual }\end{array}$ & $\begin{array}{l}\text { Elev. Motor } \\
\text { ci corte- } \\
\text { manualtloco } \\
\text { m manual }\end{array}$ & $\begin{array}{l}\text { Elex: } \\
\text { Hidráulico } \\
\text { Fcorte } \\
\text { manual+ } \\
\text { m motor c1 } \\
\end{array}$ & $\begin{array}{l}\text { Elew Hidr. } \\
\text { corte } \\
\text { manual+loc. } \\
\text { motor hidr. }\end{array}$ & $\begin{array}{l}\text { Elev Hidr+cor } \\
\text { te hidr +loc } \\
\text { motor ci }\end{array}$ & $\begin{array}{l}\text { Elev. Hidrtcor } \\
\text { te eletr. +loc } \\
\text { motor ci }\end{array}$ & & & & & \\
\hline $\begin{array}{l}\text { Grau de } \\
\text { liberdade } \\
\text { base }\end{array}$ & $\mathrm{m}$ & $y$ & $z$ & $\mathrm{xx}$ & $\mathrm{xyz}$ & $x_{m}$ & $8 x$ & & & & & \\
\hline $\begin{array}{l}\text { Grau de } \\
\text { liberdade } \\
\text { elevação }\end{array}$ & $\mathrm{x}$ & $y$ & $z$ & xy & xyz & $y z$ & $\mathrm{xxz}$ & & & & & \\
\hline
\end{tabular}

Considerando o conceito detalhado da máquina como viável, foi possível realizar o desenho conceitual da colhedora, apresentado na Figura 4, Figura 5, Figura 6, e Figura 7.

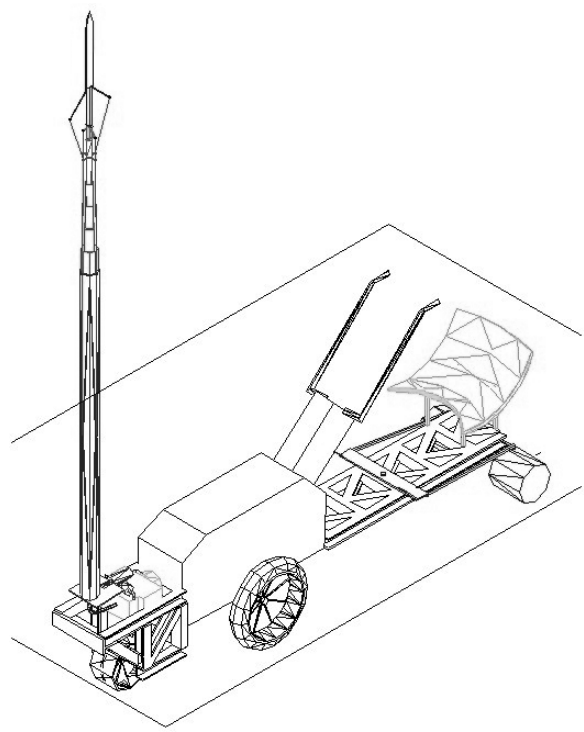

Figura 4 - Vista geral da nova colhedora de babaçu.

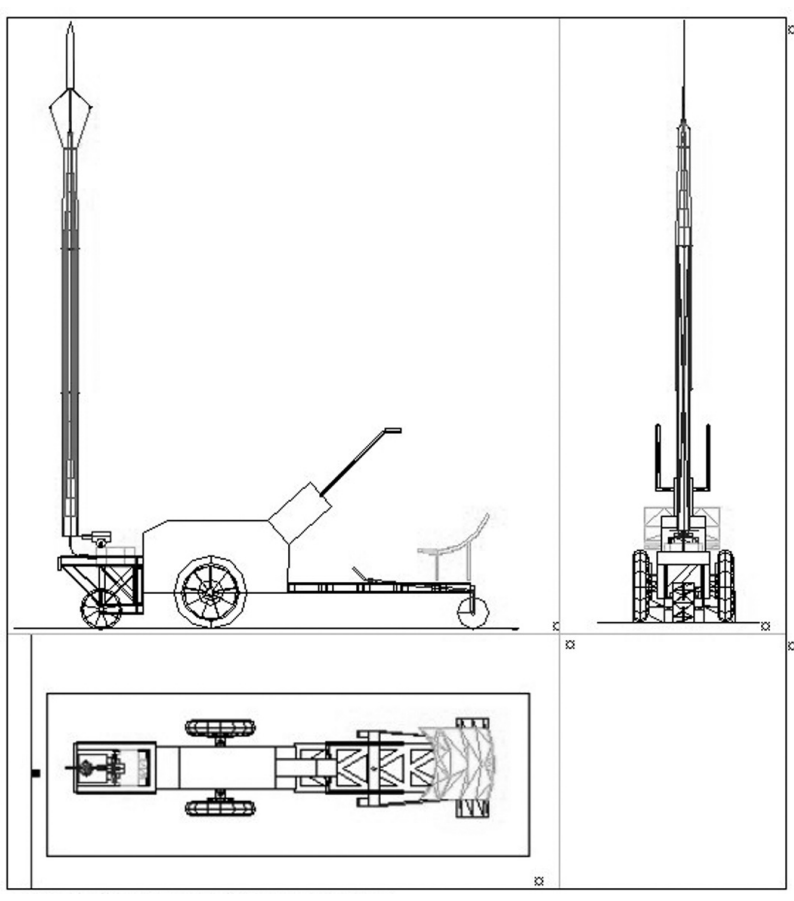

Figura 5 - Três vistas da colhedora de babaçu. 


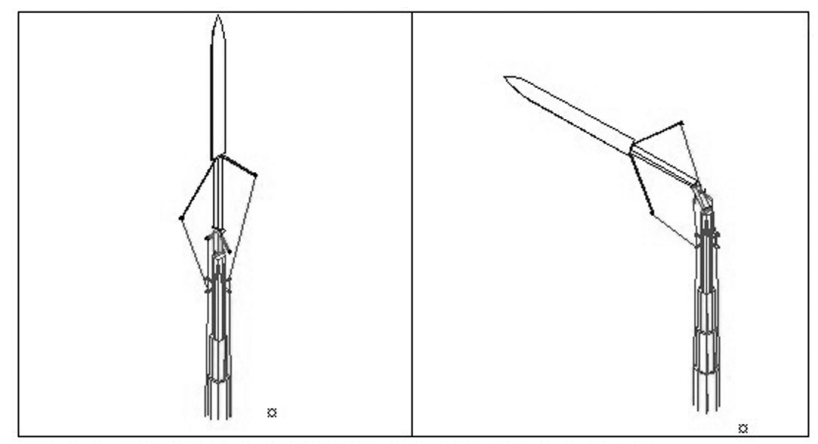

Figura 6 - Detalhe do sistema de corte articulado da colhedora de babaçu: (a) posição de descanço; (b) em operação

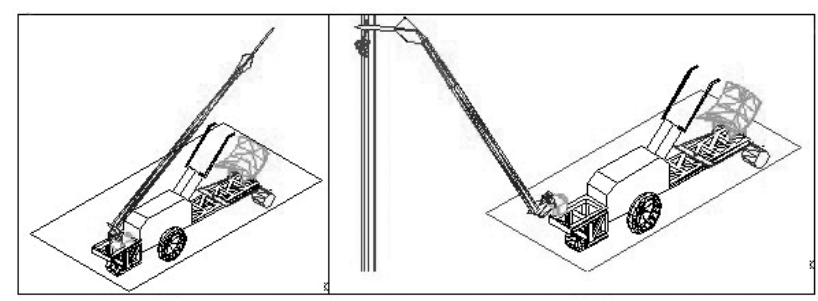

Figura 7 - (a) Haste colhedora em posição de transporte; (b) Colhedora em ação.

\section{CONCLUSÕES}

A metodologia de matriz morfológica se mostrou adequada para propor o conceito de uma colheitadeira de babaçu.

A nova máquina proposta poderá a vir ter suas estruturas e mecanismos modificados, de acordo com uma avaliação de viabilidade técnica.

Uma avaliação de viabilidade econômica se faz necessária para estabelecer custos e deduzir demandas e ofertas de máquinas.

Vislumbra-se pelo conceito apresentado que a nova colhedora de babaçu poderá operar em ambientes florestais naturais e artificiais, visto suas dimensões serem semelhantes aos animais atualmente utilizados para o transporte da coleta de babaçu.

\section{BIBLIOGRAFIA CITADA}

Back, N. 1983. Metodologia de projeto de produtos industriais. Rio de Janeiro, Guanabara Dois. 180pp.

BiodieselBR. O babaçu. <http://www.biodieselbr.com.br >. Acesso em 20/05/2006.

Clement, C. R.; Lleras Peres, E.; van Leeuwen, j. 2005. O potencial das palmeiras tropicais no Brasil: Acertos e fracassos das ultimas décadas. Agrociencias, 9, (1-2): 67-71.
EMBRAPA. 1984. Babaçu-Programa Nacional de Pesquisa. Brasília: EMBRAPA. 100pp.

Frazão, J. M. F. 2001. Alternativas econômicas para agricultura familiar assentadas em áreas de ecossistemas de babaçuais. Relatório técnico. Governo do Estado do Maranhão, São Luis. $120 \mathrm{pp}$.

Herrmann, I.; Nassar, A. M.; Marino, M. K. M.; Nunes, R. Coordenação do SAG do Babaçu: Exploração racional possível? $<$ http:// www.pensa.usp.br>. Acesso em 20/05/2006.

Frazão, J. M. F. 1992. Diagnóstico da pesquisa agroflorestal do babaçu na ultima década. In: Workshop babaçu: alternativas políticas, sociais e tecnológicas para o desenvolvimento sustentável. Anais... EMAPA. EMAP, São Luis: 75 - 89.

Kono, A. 1976. Da necessidade de programar o desenvolvimento da economia do babaçu. São Luis. 250pp.

Lopes, O.C.; Schuchardt, U.F.F. 1983. Novos catalizadores para transesterificação de óleos vegetais. Dissertação de Mestrado, Faculdade de Engenharia Agrícola da Universidade Estadual de Campinas, Campinas, SP. 103pp.

May, P. H. 1990. Palmeiras em chamas: transformação agrária e justiça social na zona de babaçu. São Luís, EMAPA/FINEP/Fundação Ford. 240pp.

MAY, P.H. 1999. Natural Resource Valuation and Policy in Brazil: Methods and Cases. Nova York, Columbia University Press. 150pp.

May, P.; Veiga Neto, F.C.; Cheves Pozo, O.V. 2000. Valoração econômcia da biodiversidade. Ministério do Meio Ambiente, Brasília. 90pp.

Teixeira, M. A. 2002. Biomassa de babaçu no Brasil. In: AGRENER2002. Anais...Campinas. NIPE-UNICAMP, Campinas: $210-220$.

UNIVERSIDADE SÃO PAULO. Babaçu. <http:// www.bibvirt. futuro.usp.br. Acesso 20/05/2006.

Homma, A. K. O. 2005. Amazônia: como aproveitar os benefícios da destruição?. Estudos Avançados, 59 (19): 20-30.

Vivacqua Filho, A. 1968. Petróleo e Coque Metalúrgico do Babaçu e Macaúba. In: Encontro do Babaçu. Anais...Teresina. SPC, Teresina: $127-136$.

Zylbersztajn, D.; Marques, C. A. S.; Nassar, A. M.; Pinheiro, C. M.; Martinelli, D. P.; Adeodato S. Neto, J.; Marino, M. K.; Nunes, R. 2000. Reorganização do agronegócio do babaçu no estado do Maranhão. Relatório técnico. Grupo Pensa-USP, São Paulo. 120pp.

Wunder, S. 1998. Value determinants of plant extractivism in Brazil. Center for Development Research, Copenhagen. 210pp.

Recebido em 17/11/2006

Aceito em 05/07/2007 